book would have been incomplete without it and some newer aspects of the subject are brought to light.

The oxidation and reduction of inorganic sulphur compounds by plants, microorganisms and animals, transformations vital to the continuing re-cycling of sulphur in nature, are described in detail in later chapters. These processes set the stage for the concluding chapters of the book which constitute a novel attempt to appraise the biological significance of inorganic sulphur compounds from both a medical and an economic standpoint.

These various approaches serve to emphasize the important role of sulphur biochemistry to life on this planet and the book represents a most useful first attempt to gather together information concerning a very diverse field of activity. To cover the subject comprehensively would have been an impossible task in anything less than an advanced treatise and not everybody will agree with the emphasis placed on different aspects by the present authors. On the whole, however, they have succeeded in producing a very readable text which will certainly be welcomed by research workers in this particular field and which could be regarded as compulsory reading for anybody contemplating entering the field for the first time.

K. S. DODGSON

\section{CAPRICIOUSNESS UNDERSTOOD}

The Science, Technology and Application of Titanium Edited by R. I. Jaffee and N. E. Promisel. (Proceedings of an International Conference held in the Royal Festival Hall, London, May 21-24, 1968.) Pp. xxi+1202. (Pergamon: Oxford, London and New York, May 1970.) $360 s ; \$ 48$.

Thrs volume comprises the proceedings of an international conference on titanium which needed the spaciousness of the Royal Festival Hall to accommodate the numerous participants. It represents the fourth milestone in the hist-ory of the titanium industry. The first was erected in 1938 by Dr Kroll when he attempted to attract commercial interest in the ductile titanium that he had produced by magnesium reduction of the chloride. Since then, at regular ten yearly intervals, widely supported scientific gatherings have assessed the state of titanium development and application. This conference is the third of these and was organized jointly by the Institute of Metals, the Metallurgical Society of the AIME and the American Society of Metals, in association with the Japan Institute of Metals and the Academy of Sciences of the USSR.

Kroll refers to titanium as "this capricious metal". The adjective may have seemed particularly apt to those who, like him, wrestled in the early days with the unfamiliar problems presented by the metal's extreme reactivity and the first encounters with hydrogen embrittlement. But in the short span of three decades titanium and some of its alloys have reached the point where at least their capriciousness is sufficiently well understood to allow them to be used with confidence where the high strength to weight ratio and special corrosion resistance meet service conditions better than other materials. It might be regarded as a sign of the attainment of its maturity that Rolls-Royce fell back on a titanium alloy for the fan blades of the RB 211 engine when 'Hyfil' became suspect because of its inadequate impact resistance. The general impression from the papers presented at this conference is of a phase of consolidation. There are many scientifically competent tidying-up operations but nothing startlingly new. The views held some time ago are confirmed that the problems arresting titanium development are in the realms of physical metallurgy, manipulation and understanding the behaviour in real engineering situations. Problems of extraction and refining are few and, indeed, were outside the terms of reference of the conference. Stress corrosion cracking and hydride embrittlement are still a source of preoccupation as is corrosion in the presence of halides. But little is said about the important problem of scrap recycling, of development of powder metallurgy techniques for alloy production or of the grievous tribological problems that titanium generates.

All in all, the volume communicates an impressive account of advance in the science and technology of titanium during three decades. It confirms the arrival of titanium as an important weapon in the armoury of the materials technologist, but emphasizes that its further development, as with sales of the present volume, will be restricted by its high cost per pound. Reference libraries, however, will need to have this book as an authoritative account of the current state of the science and technology of titanium. Aspiring Titans who wish to gauge the current climate of opinion would do well to read first the remarks of the rapporteurs who introduced the various groups of papers and the ensuing reported discussions which are particularly revealing and valuable.

K. M. Entwistle

\section{SURFACE IMPURITIES}

\section{Clean Surfaces}

Their Preparation and Characterization for Interfacial Studies. Edited by George Goldfinger. (Based on a Symposium held at North Carolina State University at Raleigh.) Pp. xix +385. (Dekker: New York, April 1970.) $178 s ; \$ 18.75$.

Ix is well known that most surfaces are more or less covered with adherent layers of other adventitious materials-adsorbed gas, liquid or solid layers, oxide or other corrosion layers, or particles such as dust, oils or sediments which have simply settled and adhered. Such layers can strongly affect the physical and chemical properties of a material, and are clearly important.

This book consists of a collection of papers presented at a conference. The result is a rather mixed group of topics which cover a wide range of materials, and it is the accounts of refined modern techniques for detecting and assessing small traces of surface impurities, even of monatomic layers or less, that make this book a useful and instructive addition to the literature.

In general, it can be said that high purity is most difficult to achieve in complex organic materials such as polymers, and the first three chapters, on polyethylene, latexes, and blood/synthetic polymer interfaces, are therefore particularly important and interesting. Chapter four outlines clearly ellipsometry as a very sensitive tool for characterization of surfaces, and chapter five (by H. E. Farnsworth) gives some recent new results illustrating procedures which give much detailed information on the cleanness of metal single-crystal surfaces in ultrahigh vacuum. Chapter six illustrates the now well known and appreciated techniques of scanning electron microscopy, which is important because it can be used to examine actual surfaces instead of replicas, with great depth of focus and resolution down to about $200 \AA$. The next four chapters deal with adsorption in gases and in solutions, involving considerations of typical data and present theories. Chapters eleven and twelve are on electrochemical techniques; and chapter thirteon is an extensive and informative account of techniques and criteria (surface tension, wetting, and the like) in the purification of aqueous solutions. The last chapters cover leached glass surfaces; pretreatment of mineral surfaces and its effect on their properties; the electronic surface states of finite lattices; impurity concentrations at "clean" oxide surfaces; and the detection and control of organic contaminants on surfaces, for example in the laboratory air, or in storage conditions. 